\title{
Drug-Induced Liver Injury After COVID-19 Vaccine
}

\author{
Rupinder Mann ${ }^{1}$, Sommer Sekhon ${ }^{2}$, Sandeep Sekhon ${ }^{3}$ \\ 1. Internal Medicine, Saint Agnes Medical Center, Fresno, USA 2. Biology, Clovis North High School, Fresno, USA 3. \\ Gastroenterology and Hepatology, Saint Agnes Medical Center, Fresno, USA
}

Corresponding author: Rupinder Mann, rupindrmann@yahoo.com

\begin{abstract}
The first case of coronavirus disease 2019 (COVID-19) was reported in December 2019 in China. World Health Organization declared it a pandemic on March 11, 2020. It has caused significant morbidity and mortality worldwide. Persistent symptoms and serious complications are being reported in patients who survived COVID-19 infection, but long-term sequelae are still unknown. Several vaccines against COVID-19 have been approved for emergency use around the globe. These vaccines have excellent safety profiles with few reported side effects.

Drug-induced hepatotoxicity is mainly seen with different drugs or chemicals. There are only a few reported cases of hepatotoxicity with vaccines. We present a case of liver injury after administration of the vaccine
\end{abstract} against the COVID-19 infection.

Review began 06/23/2021 Review ended 06/27/2021 Published 07/19/2021

๑) Copyright 2021 Mann et al. This is an open access article distributed under the terms of the Creative Commons Attribution License CC-BY 4.0., which permits unrestricted use, distribution, and reproduction in any medium, provided the original author and source are credited.
Categories: Gastroenterology, Infectious Disease, Public Health

Keywords: covid-19 vaccine, liver dysfunctions, covid-19 pandemic, covid-19, drug-induced liver injury

\section{Introduction}

A novel coronavirus, severe acute respiratory syndrome coronavirus 2 (SARS-COV-2) causing coronavirus disease 2019 (COVID-19) emerged in December 2019 in Wuhan, China, resulting in an ongoing pandemic [1]. To date, it has caused more than 173 million cases and over 3.7 million death worldwide as per World Health Organization [2]. Although the respiratory system is the most common system affected by this disease, it affects multiple organ manifestations [3]. Despite international efforts to develop treatments for this disease, there are still limited therapeutic options available with remdesivir as the only Food and Drug Administration-approved drug [4]. Given the rapid spread, high morbidity, and mortality worldwide, a coordinated effort led to developing the vaccine in a year of first diagnosed case. Multiple COVID vaccines have been developed at an unprecedented rate. These vaccines have excelled safety and efficacy profiles [57]. The most common adverse effects reported with these vaccines included mild effects like pain at the vaccine site, fever, fatigue, headache, arthralgia, myalgia, lymphadenopathy, and severe effects like anaphylactic reaction [8].

Drug-induced hepatotoxicity is a common adverse event seen with prescription and nonprescription drugs [9]. There are few reported hepatotoxicity cases due to vaccines, namely anti-rabies vaccinationinduced hepatotoxicity and autoimmune hepatitis due to influenza virus and hepatitis A and B vaccines [1017]. We report a case of liver injury after receiving the COVID vaccine.

\section{Case Presentation}

A 61-year-old female with a known history of irritable bowel disease and cholecystectomy presented to the emergency department with generalized weakness, body aches, dry heaving, and a low-grade temperature of 99.9 Fahrenheit. The patient received a second dose of the Pfizer COVID-19 vaccine nine days before the start of symptoms. She was noted to have conjunctival icterus, mild generalized abdominal tenderness without guarding, or rigidity on physical examination. On admission, the patient's vitals were stable except for tachycardia with a heart rate between 90 and 110 beats $/ \mathrm{min}$.

Laboratory analysis was remarkable for elevated alkaline phosphatase (ALP) of $207 \mathrm{U} / \mathrm{L}$, total bilirubin of 6.2 $\mathrm{mg} / \mathrm{dL}$, direct bilirubin of $3.9 \mathrm{mg} / \mathrm{dL}$, white blood cell (WBC) count of $17.2 \times 10^{9} / \mathrm{L}$, and mildly elevated aspartate transaminase of $37 \mathrm{U} / \mathrm{L}$ (Table 1 and Figure 1 ). Abdominal ultrasound showed increased echogenicity within the liver compatible with fatty infiltrates, and common duct diameter was measured to be $6 \mathrm{~mm}$. At the same time, CT of the abdomen with contrast showed no acute abnormalities. The patient was admitted to the hospital and started on empiric antibiotics for presumed cholangitis. Gastroenterology consultation was obtained. Magnetic resonance cholangiopancreatography without contrast showed no filling defect within the biliary duct, status post cholecystectomy, bile duct diameter within a normal range, and unremarkable liver. The patient remained afebrile, WBC trended down, and abdominal pain improved over the course of the hospital stay. Given these findings, infectious disease specialist recommended discontinuing antibiotics. Antibodies to liver/kidney microsomal type 1, smooth muscle, anti-mitochondrial, alpha-1 antitrypsin came back negative, and, additionally, ceruloplasmin, antinuclear antibody, alpha- 


\section{Cureus}

fetoprotein, and viral serologies for hepatitis A, B, and C came back negative (Table 2). Liver biopsy showed minimal pallor suggesting slight edema along with scattered inflammatory cells consisting of small lymphocytes, scattered polymorphonuclear leukocytes, and few eosinophils, no evidence of florid duct lesion on interface hepatitis, and no evidence of fibrosis on trichrome and reticulin stain.

45 $\because$ Aspartate transaminase (AST) (U/L) Alanine transaminase (ALT) (U/L)

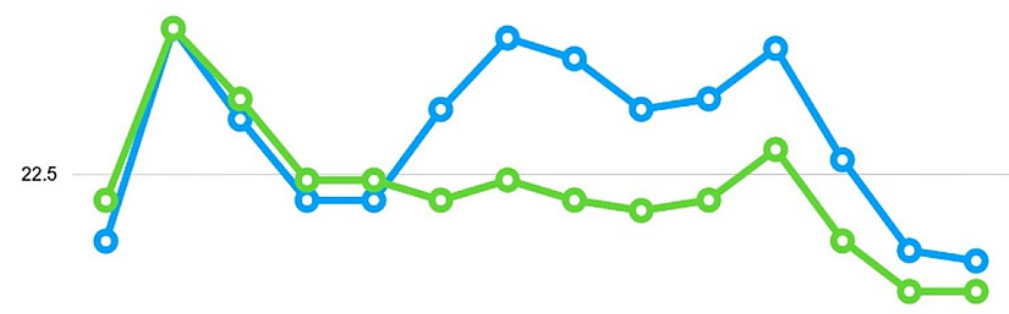

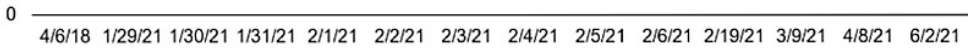
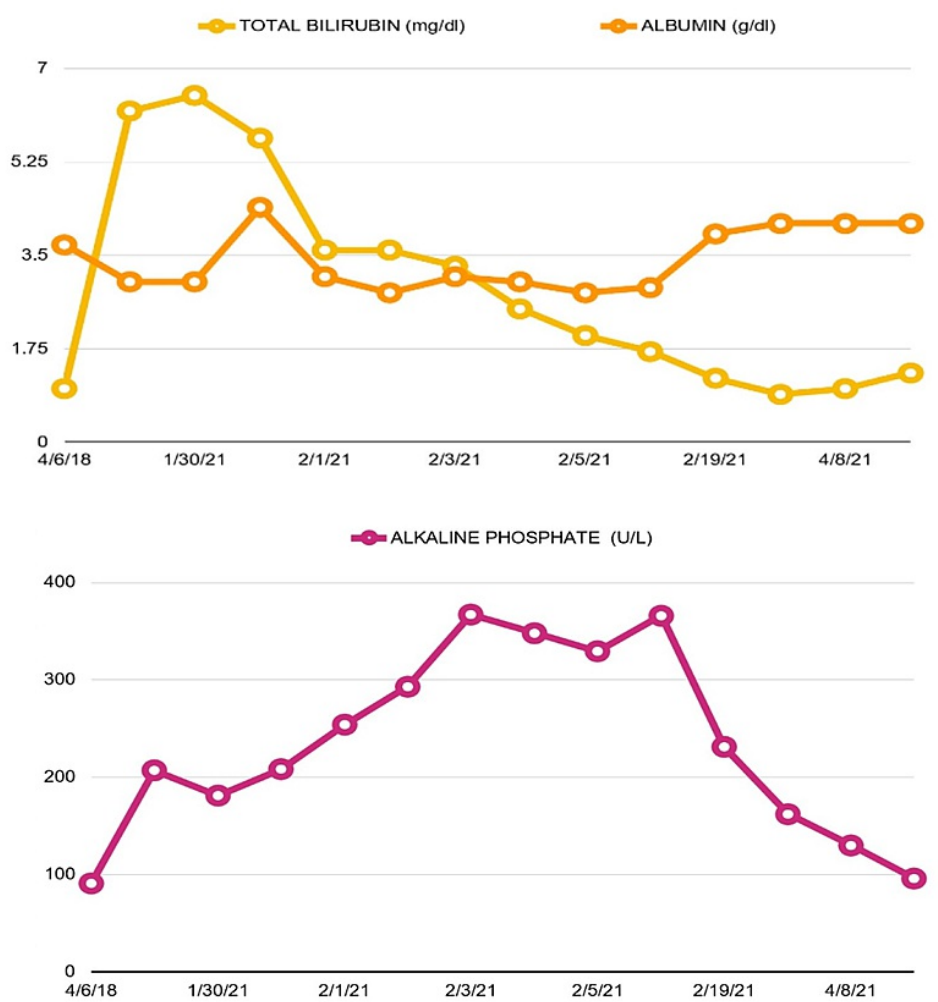

FIGURE 1: Graphs showing liver function test trends 


\section{Cureus}

\begin{tabular}{|c|c|c|c|c|c|}
\hline Date & $\begin{array}{l}\text { Aspartate transaminase } \\
\text { (U/L) }\end{array}$ & $\begin{array}{l}\text { Alanine transaminase } \\
\text { (U/L) }\end{array}$ & $\begin{array}{l}\text { Total bilirubin } \\
\text { (mg/dL) }\end{array}$ & $\begin{array}{l}\text { Alkaline phosphate } \\
\text { (U/L) }\end{array}$ & $\begin{array}{l}\text { Albumin } \\
\text { (g/dL) }\end{array}$ \\
\hline $4 / 6 / 2018$ & 16 & 20 & 1 & 91 & 3.7 \\
\hline $1 / 29 / 2021$ & 37 & 37 & 6.2 & 207 & 3 \\
\hline $1 / 30 / 2021$ & 28 & 30 & 6.5 & 181 & 3 \\
\hline 1/31/2021 & 20 & 22 & 5.7 & 208 & 4.4 \\
\hline 2/1/2021 & 20 & 22 & 3.6 & 254 & 3.1 \\
\hline $2 / 2 / 2021$ & 29 & 20 & 3.6 & 293 & 2.8 \\
\hline 2/3/2021 & 36 & 22 & 3.3 & $36 \%$ & 3.1 \\
\hline 2/4/2021 & 34 & 20 & 2.5 & 348 & 3 \\
\hline 2/5/2021 & 29 & 19 & 2 & 329 & 2.8 \\
\hline 2/6/2021 & 30 & 20 & 1.7 & 366 & 2.9 \\
\hline 2/19/2021 & 35 & 25 & 1.2 & 231 & 3.9 \\
\hline 3/9/2021 & 24 & 16 & 0.9 & 162 & 4.1 \\
\hline 4/8/2021 & 15 & 11 & 1 & 130 & 4.1 \\
\hline $6 / 2 / 2021$ & 14 & 11 & 1.3 & 96 & 4.1 \\
\hline
\end{tabular}

\section{TABLE 1: Liver function tests trend}

\begin{tabular}{|c|c|}
\hline Test & Results \\
\hline Gamma-glutamyl transpeptidase & $103 \mathrm{U} / \mathrm{L}$ (1-24 U/L reference range) \\
\hline Hepatitis A lgM antibody & Negative \\
\hline Hepatitis B surface antigen & Negative \\
\hline Hepatitis B core IgM antibody & Negative \\
\hline Hepatitis C antibody & Negative \\
\hline Anti-liver/kidney microsomal antibody & Negative ( $\leq 20=$ negative, reference range) \\
\hline Ferritin & $975.2 \mathrm{ng} / \mathrm{mL}$ (10.0-291.0 reference range) \\
\hline Antinuclear antibody reflex & Negative \\
\hline Smooth muscle antibody & Negative \\
\hline Anti-mitochondrial antibody & Negative ( $\leq 20$ = negative, reference range) \\
\hline Ceruloplasmin & $38 \mathrm{mg} / \mathrm{dl}$ (18-53 mg/dL reference range) \\
\hline
\end{tabular}

\section{TABLE 2: Immunologic and infectious work-up for liver disease}

Given that all work-up for infection, autoimmune diseases, and any obstruction came back negative, the patient's clinical picture and laboratory findings were attributed as a liver injury due to the COVID-19 vaccine. Her liver function levels continued to trend down, and she was discharged from the hospital after a week of hospitalization. On the patient's follow-up with a gastroenterologist, abdominal pain was resolved, and her liver function test values normalized (Table 1 and Figure 1 ).

\section{Discussion}


Drug-induced hepatotoxicity leads to nearly $10 \%$ of all cases of acute hepatitis and more than $50 \%$ cases of liver failure [18]. It is one of the common reasons for the withdrawal of medications from the market and modification of use [19]. It can be either type A (predictable), dose-related and short latent period in days, or type B (idiosyncratic), dose-independent, unpredictable, and variable latency [20,21]. Based on populationbased studies, drug-induced liver injury incidence varies between 13.9 and 19.1 cases per 100,000 people per year [22,23]. Patients have either hepatocellular injury (three times upper limit of transaminase in comparison to ALP), cholestatic injury (three times increase in ALP comparison to transaminase), or mixed pattern (where both ALP and aminotransferase are three times upper limit) [24-26]. Most patients improve spontaneously after the removal of the offending drug. If acute liver failure (ALF) is suspected, early liver transplant referral is important due to high ALF mortality [25,27].

From the spontaneous reports from patients who received Pfizer/BioNTech BNT162b2 mRNA in the UK between $9 / 12 / 20$ and 26/05/2021, there are reports of 45 patients having abnormal liver function analysis and three patients having drug-induced liver injury [28].

In this case, the review of medications and history did not reveal any other reason for hepatotoxicity. She also denied the use of any over-the-counter medications or supplements. Although it is rare with vaccination, the COVID-19 vaccine is likely the cause of hepatotoxicity in our patient based on a diagnosis of exclusion. In this case, the patient had a cholestatic pattern with elevated ALP and bilirubin with mild elevation in the transaminases.

Pfizer/BioNTech BNT162b2 mRNA trial included only 0.6\% (217/37,706) patients with liver disease. Among patients with liver disease, 214 were with mild liver disease and only three with moderate to severe liver disease. This patient has underlying fatty liver disease. It is unclear if that was a likely risk factor for hepatotoxicity in this case [5]. Although only a small number were included in trials for Pfizer/BioNTech BNT162b2 mRNA, Moderna mRNA-1273, and the AstraZeneca/University of Oxford ChAdOx1-nCoV-19 chimpanzee adenovirus vector vaccine, both the American Association for Study of Liver Diseases and European Association for the Study of Liver recommend vaccination against SARS-COV-2 with these highly effective and safe vaccines, given a greater risk of health consequences from SARS-COV-2 infection in these patients $[29,30]$.

Hepatotoxicity can occur with vaccines, even though it is more common with prescription and nonprescription drugs. So, the clinician should be watchful in patients showing clinical signs and symptoms after a vaccine.

\section{Conclusions}

In summary, we presented a case of liver injury after the COVID-19 vaccine. We attributed the cause of liver injury to the COVID-19 vaccine, given no other cause in our patient after extensive work-up. There are reports of drug-induced liver injury and abnormal liver function analysis from the spontaneous reports from patients who received Pfizer/BioNTech BNT162b2 mRNA COVID-19 vaccine in the UK. The purpose of this manuscript is to raise awareness of potential side effects; it should not alter the recommendation of healthcare providers regarding vaccinations.

\section{Additional Information \\ Disclosures}

Human subjects: Consent was obtained or waived by all participants in this study. Conflicts of interest: In compliance with the ICMJE uniform disclosure form, all authors declare the following: Payment/services info: All authors have declared that no financial support was received from any organization for the submitted work. Financial relationships: All authors have declared that they have no financial relationships at present or within the previous three years with any organizations that might have an interest in the submitted work. Other relationships: All authors have declared that there are no other relationships or activities that could appear to have influenced the submitted work.

\section{References}

1. Lu R, Zhao X, Li J, et al.: Genomic characterisation and epidemiology of 2019 novel coronavirus: implications for virus origins and receptor binding. Lancet. 2020, 395:565-74. 10.1016/S01406736(20)30251-8

2. WHO Coronavirus Disease (COVID-19) Dashboard. (2021). Accessed: June 30, 2021: https://covid19.who.int/.

3. Mehta OP, Bhandari P, Raut A, Kacimi SEO, Huy NT: Coronavirus disease (COVID-19): comprehensive review of clinical presentation. Front Public Health. 2020, 8:582932. 10.3389/fpubh.2020.582932

4. NIH: COVID-19 Treatment Guidelines Panel. Coronavirus Disease 2019 (COVID-19) Treatment Guidelines . (2021). Accessed: June 30, 2021: https://www.covid19treatmentguidelines.nih.gov/.

5. Polack FP, Thomas SJ, Kitchin N, et al.: Safety and efficacy of the BNT162b2 mRNA Covid-19 vaccine . N Engl J Med. 2020, 383:2603-15. 10.1056/NEJMoa2034577

6. Voysey M, Clemens SAC, Madhi SA, et al.: Safety and efficacy of the ChAdOx1 nCoV-19 vaccine (AZD1222) against SARS-CoV-2: an interim analysis of four randomised controlled trials in Brazil, South Africa, and the UK. Lancet. 2021, 397:99-111. 10.1016/S0140-6736(20)32661-1 
7. Baden LR, El Sahly HM, Essink B, et al.: Efficacy and safety of the mRNA-1273 SARS-CoV-2 vaccine . N Engl J Med. 2021, 384:403-16. 10.1056/NEJMoa2035389

8. Meo SA, Bukhari IA, Akram J, Meo AS, Klonoff DC: COVID-19 vaccines: comparison of biological, pharmacological characteristics and adverse effects of Pfizer/BioNTech and Moderna Vaccines. Eur Rev Med Pharmacol Sci. 2021, 25:1663-9. 10.26355/eurrev_202102_24877

9. Kosanam S, Boyina R: Drug-induced liver injury: a review . Int J Pharmacol Res. 2014, 5:10.7439/ijpr.v5i2.1507

10. Önlen Y, Savaş L, Özer B, İris NE: The elevation of liver enzymes due to Hepatitis B vaccine . Eur J Gen Med. 2006, 3:197-200. 10.29333/ejgm/82411

11. Sasaki T, Suzuki Y, Ishida K, Kakisaka K, Abe H, Sugai T, Takikawa Y: Autoimmune hepatitis following influenza virus vaccination: two case reports. Medicine (Baltimore). 2018, 97:e11621. 10.1097/MD.0000000000011621

12. van Gemeren MA, van Wijngaarden P, Doukas M, de Man RA: Vaccine-related autoimmune hepatitis: the same disease as idiopathic autoimmune hepatitis? Two clinical reports and review. Scand J Gastroenterol. 2017, 52:18-22. 10.1080/00365521.2016.1224379

13. Berry PA, Smith-Laing G: Hepatitis A vaccine associated with autoimmune hepatitis . World J Gastroenterol. 2007, 13:2238-9. 10.3748/wjg.v13.i15.2238

14. Perumalswami P, Peng L, Odin JA: Vaccination as a triggering event for autoimmune hepatitis . Semin Liver Dis. 2009, 29:331-4. 10.1055/s-0029-1233537

15. Veerappan GR, Mulhall BP, Holtzmuller KC: Vaccination-induced autoimmune hepatitis. Dig Dis Sci. 2005, 50:212-3. 10.1007/s10620-005-1303-Z

16. Csepregi A, Treiber G, Röcken C, Malfertheiner P: Acute exacerbation of autoimmune hepatitis induced by Twinrix. World J Gastroenterol. 2005, 11:4114-6. 10.3748/wjg.v11.i26.4114

17. Rajegowda RY, Nanjappa NB, Muthahanumai NK: Anti-rabies vaccination induced hepatotoxicity - a case report. Int J Basic Clin Pharmacol. 2016, 5:2280-2. 10.18203/2319-2003.ijbcp20163276

18. Frider B, Bruno A, Ponte M, Amante M: Drug-induced liver injury caused by adalimumab: a case report and review of the bibliography. Case Reports Hepatol. 2013, 2013:406901. 10.1155/2013/406901

19. Kaplowitz N: Idiosyncratic drug hepatotoxicity. Nat Rev Drug Discov. 2005, 4:489-99. 10.1038/nrd1750

20. Kaplowitz N: Drug-induced liver injury. Clin Infect Dis. 2004, 38 Suppl 2:S44-8. 10.1086/381446

21. Verma S, Kaplowitz N: Diagnosis, management and prevention of drug-induced liver injury . Gut. 2009, 58:1555-64. 10.1136/gut.2008.163675

22. Sgro C, Clinard F, Ouazir K, et al.: Incidence of drug-induced hepatic injuries: a French population-based study. Hepatology. 2002, 36:451-5. 10.1053/jhep.2002.34857

23. Björnsson ES, Bergmann OM, Björnsson HK, Kvaran RB, Olafsson S: Incidence, presentation, and outcomes in patients with drug-induced liver injury in the general population of Iceland. Gastroenterology. 2013, 144:1419-25, 1425.e1-3; quiz e19-20. 10.1053/j.gastro.2013.02.006

24. Fisher K, Vuppalanchi R, Saxena R: Drug-induced liver injury. Arch Pathol Lab Med. 2015, 139:876-87. 10.5858/arpa.2014-0214-RA

25. Katarey D, Verma S: Drug-induced liver injury. Clin Med (Lond). 2016, 16:s104-9. 10.7861/clinmedicine.166-s104

26. Teschke R: Idiosyncratic DILI: analysis of 46,266 cases assessed for causality by RUCAM and published from 2014 to early 2019. Front Pharmacol. 2019, 10:730. 10.3389/fphar.2019.00730

27. Tujios SR, Lee WM: Acute liver failure induced by idiosyncratic reaction to drugs: challenges in diagnosis and therapy. Liver Int. 2018, 38:6-14. 10.1111/liv.13535

28. print C-mPBva: All UK Spontaneous Reports Received Between 9/12/20 and 26/05/21 for mRNA Pfizer/BioNTech Vaccine Analysis Print. 2021.

29. Fix OK, Blumberg EA, Chang KM, et al.: AASLD Expert Panel consensus statement: vaccines to prevent COVID-19 infection in patients with liver disease. Hepatology. 2021, 10.1002/hep.31751

30. Cornberg M, Buti M, Eberhardt CS, Grossi PA, Shouval D: EASL position paper on the use of COVID-19 vaccines in patients with chronic liver diseases, hepatobiliary cancer and liver transplant recipients. J Hepatol. 2021, 74:944-51. 10.1016/j.jhep.2021.01.032 